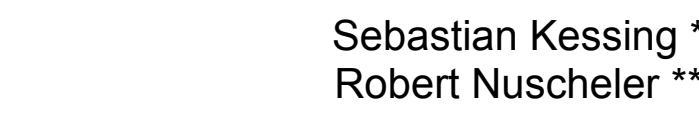

Monopoly Pricing with Negative Network Effects: the Case of Vaccines

* Freie Universität Berlin and European University Institute ** Wissenschaftszentrum Berlin für Sozialforschung

SP II 2003-06

June 2003

ISSN Nr. $0722-6748$

Research Area

Markets and Political Economy

Research Unit

Market Processes and Governance
Forschungsschwerpunkt

Markt und politische Ökonomie

Abteilung

Marktprozesse und Steuerung 
Zitierweise/Citation:

Sebastian Kessing, Robert Nuscheler, Monopoly Pricing with Negative Network Effects: the Case of Vaccines, Discussion Paper SP || 2003 - 06, Wissenschaftszentrum Berlin, 2003.

Wissenschaftszentrum Berlin für Sozialforschung gGmbH, Reichpietschufer 50, 10785 Berlin, Germany, Tel. (030) 25491 - 0 Internet: www.wz-berlin.de 


\title{
ABSTRACT
}

\section{Monopoly Pricing with Negative Network Effects: the Case of Vaccines}

\author{
by Sebastian Kessing and Robert Nuscheler *
}

We study the market for vaccinations considering income heterogeneity on the demand side and monopoly power on the supply side. A monopolist has an incentive to exploit the external effect of vaccinations and leave the poor susceptible in order to increase the willingness to pay of the rich. Even the possibility to perfectly price discriminate does not remove this incentive. Pigouvian subsidies may even make things worse. Mandatory vaccination programs covering only the poor succeed in eradicating the disease. This offers an efficiency based rationale for distribution-oriented national or international public health interventions.

Keywords: Vaccination, monopoly pricing, price discrimination, negative network effects, Pigouvian subsidies, mandatory vaccination programs

JEL Classification: D42, D62, H23, I11, 118

\section{ZUSAMMENFASSUNG}

\section{Monopolpreisbildung mit negativen Netzwerkeffekten am Beispiel von Impfstoffen}

Wir untersuchen den Markt für Impfstoffe, wobei wir Einkommensungleichheit auf der Nachfrageseite und Monopolmacht auf der Angebotsseite unterstellen. Ein Monopolist hat den Anreiz, den externen Effekt von Impfungen auszunutzen. So wird er die Armen strategisch ungeimpft lassen, um die Zahlungsbereitschaft der Reichen zu erhöhen. Selbst für den Fall der perfekten Preisdiskriminierung bleibt dieser Anreiz bestehen. Pigou Subventionen können das Marktergebnis noch verschlechtern. Staatliche Impfprogramme, die nur die Armen abdecken, können die Krankheit auslöschen. Dies liefert eine effizienzbasierte Begründung für verteilungsorientierte nationale wie internationale Interventionen in den Impfmarkt.

\footnotetext{
* We thank Kai A. Konrad, Helmut Bester, Johannes Münster, the participants of the Microeconomic Colloquium at the Freie Universität Berlin, and the participants of the CEPR workshop on "health economics and public policy" in Bergen for helpful comments. The usual caveat applies.
} 


\section{Introduction}

Traditionally, vaccinations were regarded as one of the prime examples of positive externalities. Consequently, government intervention in the form of mandatory vaccinations and Pigouvian subsidies were considered to be appropriate policy responses to the distortions caused by the externality. More recently, this traditional view has been challenged by various contributions that produced a number of somewhat conflicting results about the form and optimality of government intervention in the market for vaccines (see e.g. Brito et al. (1991), Francis (1997), and Geoffard and Philipson (1997)). These results typically depend on the specific assumptions made in the models about agent heterogeneity, market structure and dynamics. This paper contributes to this literature by considering strategic incentives and optimal government responses in the context of two hitherto neglected dimensions. First, individuals are assumed to differ with respect to income. Second, monopoly power on the supply side is considered.

In the existing theoretical literature agent heterogeneity is usually introduced, if at all, through the assumption that the disutility of vaccinations, i.e. side effects, varies. Empirically, disutility is difficult to observe. As empirical studies of individual vaccination decisions usually find a clear positive relationship between income and the probability of being vaccinated, introducing agent heterogeneity into the theoretical analysis through income differences would seem to be a natural step. Philipson (1996, table 2, p. 624), for example, finds a positive income effect on the probability of measles vaccination for children in the U.S. England et al. (2001, p. 19) report that, if there is a fee, as with hepatitis B in China, "poorer people are more likely to go without essential immunization". Moreover, since government action usually affects people's incomes, such an analysis promises to be a better approximation of the consequences of different policy measures.

The second key element in our treatment is its focus on monopoly power on the supply side. This assumption is motivated by recent developments in the vaccine industry. Important changes in U.S. legislation in 1986, which effectively shield manufacturers from the liability risk of new vaccines, resulted in a substantial increase in R\&D efforts and these have recently lead to a dramatic increase in the availability of a number of new 
vaccines (BusinessWeek Online (2002)). Russell (2002) points out that two developments have also increased monopoly power significantly. First, there has been a shift from commodity vaccines to vaccines which are heavily protected by intellectual property rights. The new Hepatitis B vaccine introduced in the late 1980s has for example about thirty associated patents. Similarly, Reiss and Strauss (1998) document that between 1980 and 1995 patent applications for vaccines at the European patent office rose by a factor of seven and that this development has been fuelled by the progress made in the field of genetically engineered vaccines in particular. ${ }^{1}$ Second, the ongoing concentration in the industry at all levels, from research and development to marketing organizations, has left only a few key players. Furthermore, as firms are increasingly specializing in specific diseases and their core fields of expertise, competitive pressure is being further attenuated.

A vaccine monopolist has two main incentives: (i) to keep the disease alive and (ii) to increase the prevalence of the disease in order to increase the willingness to pay for vaccination. $^{2}$ In their dynamic model Geoffard and Philipson (1997) address the first incentive, but remain silent about the second incentive. We provide the missing part of the analysis using a static model. On the demand side, we consider the case where the population has to pay for the vaccinations, i.e. the costs are not covered by health insurance companies or the state. Consequently, there is no bargaining either between insurance companies or state agencies. ${ }^{3}$

We summarize both the income dependence of the individual willingness to pay and the external effect of a reduced infection probability due to a higher number of vaccinated individuals using a simple linear aggregate demand schedule faced by the monopolist.

\footnotetext{
1 "The four industry leaders (Merck, GlaxoSmithKline, Aventis Pasteur, and Wyeth) are estimated to spend more than US\$750 million a year on vaccine R\&D - as much as a fivefold jump at some companies since 1992." (BusinessWeek Online (2002))

${ }^{2}$ Although not in a monopoly context, the case of measles offers some insights: more than 99 percent of the disease burden of measles fall on low and middle income countries, with more than 750,000 deaths in the year 2000. Full immunization could save roughly 28 million disability adjusted life years (see Kremer (2002, pp. 70-71)).

${ }^{3}$ For an empirical analysis that tests whether price discrimination or bargaining is present in the U.S. vaccine market see Kauf (1999).
} 
The linearity assumption allows explicit results to be obtained, but none of the results depend on it qualitatively. The decisive element in this setting is the monopolist's second strategic incentive mentioned above. This is most easily analyzed in a static environment. But the results will also apply in a dynamic framework, since the importance of the external effect increases. ${ }^{4}$ Although the emphasis of the analysis is on the case without price discrimination we also consider perfect price discrimination. All qualitative results, including the comparative statics, are robust. With price discrimination, vaccination discrimination is in fact reduced. But, in contrast to the standard model without external effects, the outcome may still be inefficient. The findings of the robustness of the strategic incentives are relevant for policy recommendations since multi-tier pricing is pervasive in real world vaccine markets (Russell (2002)). ${ }^{5}$

In the theory of public goods, the problem of under-provision can be eliminated by Pigouvian subsidies. However, although vaccinations are an example of privately provided public goods, subsidies do not work very well. At first demand increases as the individual price is reduced. However, this increase lowers the infection probability and thus reduces the willingness to pay. This counteracting effect limits the effect of these subsidies (see Geoffard and Philipson (1997, p. 225)). We show that subsidies may make things even worse. We assume that the price subsidy is financed by lump-sum taxation creating a negative income effect. If this effect is sufficiently large, the positive price effect is overcompensated and a smaller proportion of people are vaccinated. This contrasts with the classical regulation arguments for Pigouvian subsidies and strengthens Philipson's (2000) argument, that "Pigouvian subsidies traditionally seen as resolving the underprovision problem of vaccines can be short-run, or out of steady state, arguments" (p. 1777), since these may even fail in static settings. Recently, Philipson and Mechoulan (2003) have argued that subsidies are likely to distort R\&D incentives.

\footnotetext{
${ }^{4}$ Francis (1997) showed that in his dynamic setting the externality disappears. The allocation is efficient. But with heterogenous individuals this result does not generally hold.

${ }^{5}$ The UN Accelerating Access Initiative supports differential pricing for AIDS drugs (see http://www.unaids.org/acc_access/). In this context Roche was more or less forced to increase the discount on their AIDS drugs for developing countries to roughly 90 percent of the Swiss price (see Médecins Sans Frontières (2003)).
} 
Another public policy usually suggested is mandatory vaccination. If mandatory vaccination programs do not cover the whole population, the people vaccinated lower the probability that the susceptible will be infected. The willingness to pay is reduced, i.e., mandatory demand crowds out voluntary demand. This is a standard argument for why it is difficult to eradicate a disease by mandatory vaccination if not the entire population is included in the program (see Philipson (2000, p. 1781)). However, such a program is much more effective with income-dependant demand: as people's incomes differ, the public program can cover the poor and the monopolist the rich. Of course the willingness to pay of the rich is reduced, but it remains relatively high due to the income effect. Full vaccination can be achieved with a mandatory participation rate that is strictly smaller than one. Thus, our analysis provides an efficiency argument for public health vaccination programs that focus on the poor like those typically supported by the World Health Organization (WHO) and the Worldbank.

The approach presented here is related to Brito et al. (1991). They consider a static model with a continuum of individuals whose disutility from vaccination differs. Since vaccines are provided free of charge, price discrimination cannot be studied in their setting. The first-best outcome can be implemented by subsidizing those who decide to vaccinate, or by taxing those without immunization. But when the subsidy has to be financed through taxation, the first-best can only be attained under the strong assumption of identical marginal utility of income across individuals. In their dynamic model, Geoffard and Philipson (1997) address the question of disease eradication. Both price subsidies and mandatory vaccination programs have limited impact, since the positive effects of the respective policies are partly offset by the negative effect of the externality.

The current paper is also related to the literature on network externalities, e.g. Bensaid and Lesne (1996), Cabral et al. (1999), and Mason (2000). The main difference is the sign of the network effect. This is positive in these models but negative in ours, leading to completely different results. With a positive network effect, introductory pricing may occur to built up a certain critical network size. With vaccinations it is the other way round: in order to prevent the market shrinking or disappearing a critical mass will never be exceeded. 
The paper is organized as follows: in section 2 we present the main ingredients of our model. The monopolist's price setting problem and the comparative static properties of this solution are studied in section 3. Perfect price discrimination is analyzed in section 4. In section 5 we discuss public policies that may be used to reduce discrimination and thus increase social welfare. Section 6 concludes. The appendix provides a generalization of the reduced form applied throughout the paper.

\section{The model}

Consider a population of mass one with individuals who differ in income but are otherwise homogenous. Income is denoted $a$ and is continuously distributed on the interval $\left[a_{L}, a_{H}\right]$, where $0<a_{L} \leq a_{H}$. An individual's willingness to pay for vaccination depends on her income $a$ and the expected share of individuals who get vaccination, $\theta^{e} \in[0,1]$ :

$$
p=p\left(\theta^{e}, a\right)
$$

The higher the expected rate of immunization $\theta^{e}$, the lower the expected share of susceptible individuals $1-\theta^{e}$. A high $\theta^{e}$ is associated with a low expected risk of infection $\pi^{e}, \partial \pi^{e} / \partial \theta^{e}<0$. Clearly, the willingness to pay for vaccination increases in the risk of infection. We thus postulate $\partial p / \partial \theta^{e}<0$, which captures the external effect of vaccinations. Furthermore, in line with the empirical evidence, it is assumed that the willingness to pay increases in income $\partial p / \partial a>0$. While the external effect of vaccinations is a general feature of the market, a positive income effect is not so obvious. In the appendix, interpreting vaccination as an insurance decision, we derive a sufficient condition on preferences for yielding a positive income effect. Finally, we assume $p(1, a)>0$, implying the existence of an exogeneous infection risk. While made for simplicity, this can be justified by infection threats from other countries ${ }^{6}$, accidental laboratory outbreaks, or terrorist attacks ${ }^{7}$.

\footnotetext{
${ }^{6}$ The way infectious diseases can spread around the world can be seen currently with the Severe Acute Respiratory Syndrome (SARS) that originated in China.

${ }^{7}$ Although smallpox is said to be eradicated, there is a positive willingness to pay for vaccines.
} 
To simplify the analysis, and in order to derive explicit closed form solutions, we summarize the individual willingness to pay by the following simple linear scheme

$$
p\left(\theta^{e}, a\right)=z_{\theta}\left(1-\theta^{e}\right)+z_{a} a
$$

where $z_{a} \in(0,1)$ measures the income effect and $z_{\theta}>0$ the importance of the external effect. The upper bound on $z_{a}$ is justified by normality, while the lower bound reflects our central assumption of a positive income effect. Furthermore we assume that the population is uniformly distributed on the interval $\left[a_{L}, a_{H}\right]$. None of these assumptions is necessary for the results we derive below. However, their use significantly eases the presentation of the main ideas. As will become clear, a downward sloping aggregate demand function is sufficient for most results. We discuss the conditions under which demand is downward sloping in the appendix.

There is a monopolist who provides a vaccine that yields perfect protection against the disease and that has no side effects. His price setting problem is analyzed in a two stage game. At stage 1 the monopolist sets the price $p_{m}$. We analyze two versions of the game, in section 3 we study standard monopoly pricing. Here $p_{m}$ is constant and denotes the price at which the monopolist is willing to sell to all consumers actually demanding vaccination. In section 4 the case of perfect price discrimination is addressed. The price may depend on income so that $p_{m}=p_{m}(a)$ is a price schedule. At stage 2 individuals observe prices, form expectations about the vaccination rate, and thus about the infection probability, and decide whether to vaccinate or not, i.e. aggregate demand is realized.

Solving the game backwards leads to a subgame perfect Nash equilibrium. Deriving aggregate demand requires first analyzing the role of consumers' expectations for vaccination decisions. As the analyses differ for the two cases studied they are relegated to the respective sections of the paper (see lemma 1 and lemma 3 below). Once aggregate demand is derived, determining the monopolist's optimal policy is straightforward.

\section{Monopoly pricing}

Let us first consider the case of standard monopoly pricing where the monopolist only quotes a single price. In order to derive the stage two vaccination equilibrium we assume 
symmetric expectations and require expectations to be consistent, i.e. expectations must be fulfilled in equilibrium. The second useful property is the sorting of individuals by income. In particular, for a given expected infection risk, an individual who decides to be vaccinated knows that everybody richer than herself will also be vaccinated.

Before we solve for the equilibrium of the vaccination subgame, we define the critical consumer $\bar{\theta}$. Let $p_{m}>0$ be some fixed price for the vaccine, then $\bar{\theta}=\bar{\theta}\left(p_{m}\right)$ solves

$$
p_{m}=p(\bar{\theta}, a(\bar{\theta}))=z_{\theta}(1-\bar{\theta})+z_{a}\left(a_{H}-\bar{\theta} \Delta\right),
$$

where $\Delta:=a_{H}-a_{L}$. The income of the critical consumer is $\bar{a}:=a(\bar{\theta})=a_{H}-\bar{\theta} \Delta$. Since the willingness to pay $p(\bar{\theta}, a(\bar{\theta}))$ strictly decreases in $\bar{\theta}$, the critical consumer is well-defined, i.e. $\bar{\theta}$ is unique.

In lemma 1 we show that there are unique expectations for every given price $p_{m}$. How consistency of expectations can be used to derive the aggregate demand is demonstrated in lemma 2.

Lemma 1 Individuals facing a price $p_{m}$ will rationally expect $\bar{\theta}\left(p_{m}\right)$ to be the immunization rate.

Proof. The proof is by contradiction. So, suppose that individuals expect the immunization rate $\theta^{e}>\bar{\theta}$. Then, the willingness to pay for vaccination of type $\bar{\theta}$ is $p\left(\theta^{e}, a(\bar{\theta})\right)=z_{\theta}\left(1-\theta^{e}\right)+z_{a}\left(a_{H}-\bar{\theta} \Delta\right)<p_{m}$. Individual $\bar{\theta}$ will not demand vaccination and neither will all consumers with lower income than $a_{H}-\bar{\theta} \Delta$. Thus immunization with expectations $\theta^{e}>\bar{\theta}$ will actually be lower than $\bar{\theta}$ so that expectations can never be confirmed. A similar reasoning applies to all $\theta^{e}<\bar{\theta}$ proving inconsistency of all $\theta^{e} \neq \bar{\theta}$.

The lemma implies that we can concentrate on cases where the two arguments of the willingness to pay function are identical. To ease notation we will thus write $p(\theta):=$ $p(\theta, a(\theta))$. Notice that we also omit the bar.

Lemma 2 The aggregate demand function the monopolist is facing at the first stage of the game is given by

$$
\theta\left(p_{m}\right)=\frac{z_{\theta}+z_{a} a_{H}-p_{m}}{z_{\theta}+z_{a} \Delta}
$$


Proof. Since the vaccination equilibrium at price $p_{m}$ is fully characterized by $\bar{\theta}\left(p_{m}\right)$, deriving aggregate demand simply requires solving equation (3) for $\bar{\theta}$.

Given these lemmata, the game boils down to a game of complete information. By setting the price, the monopolist can directly influence expectations about the immunization rate and thus exploit the external effect associated with vaccinations. Alternatively the monopolist's policy may be derived by optimization with respect to $p$ or $\theta$. For notational convenience we stick to the latter yielding the following objective function

$$
\Pi(\theta)=p(\theta) \theta=\left(z_{\theta}(1-\theta)+z_{a}\left(a_{H}-\theta \Delta\right)\right) \theta .
$$

We consider constant marginal costs of zero, implying disease eradication, i.e. $\theta=1$, as being socially optimal. The first order condition is derived by differentiation yielding ${ }^{8}$

$$
\theta^{*}=\frac{z_{\theta}+z_{a} a_{H}}{2\left(z_{\theta}+z_{a} \Delta\right)}
$$

Without the externality, the monopolist would face the inverse demand schedule $p(\theta)=$ $z_{\theta}+z_{a}\left(a_{H}+\theta \Delta\right)$ yielding an optimal supply of $\frac{z_{\theta}+z_{a} a_{H}}{2 z_{a} \Delta}>\theta^{*}$. With the externality, the monopolist has an incentive to reduce supply in order to increase the willingness to pay and thus profit. The externality reduces the elasticity of demand and thereby amplifies monopoly power. This interpretation demonstrates that this result is very general. It holds as long as aggregate demand is downward sloping. ${ }^{9}$ The price corresponding to $\theta^{*}$ is

$$
p_{m}^{*}=\frac{z_{\theta}}{2}+z_{a} a_{H}
$$

The price increases in all exogenous parameters except $a_{L}$. The comparative static properties of $\theta^{*}$ are much more informative. First, note that $\partial \theta^{*} / \partial z_{a}>0$. With an increasing income effect, the relative importance of the external effect of vaccinations is reduced and with it the incentive to cut the supply. More interesting is the effect of a change in the external effect parameter $z_{\theta}$ which is clearly negative, i.e. $\partial \theta^{*} / \partial z_{\theta}<0$. The higher the external effect of susceptible individuals on the willingness to pay, the higher

\footnotetext{
${ }^{8}$ To avoid $\theta^{*}$ exceeding one, it is assumed that $z_{\theta}+z_{a}\left(\Delta-a_{L}\right) \geq 0$.

${ }^{9}$ See the appendix for a condition for preferences that yield a downward sloping demand.
} 
the monopolists' incentive to exploit this effect, i.e. to reduce the amount of vaccines sold.

To study the effect of income inequality on equilibrium let $a_{H}=a+\Delta / 2$ and $a_{L}=a-\Delta / 2$. Then $\theta^{*}=\frac{z_{\theta}+z_{a}(a+\Delta / 2)}{2\left(z_{\theta}+z_{a} \Delta\right)}$. The income inequality effect is observed by differentiation with respect to $\Delta$ yielding $\partial \theta^{*} / \partial \Delta<0$. The more unequally the income is distributed among the population, the more severe the problem of vaccination discrimination. Note that the average income $a$ is not affected by changes in $\Delta$. Now consider that the population as a whole becomes richer, but (absolute) inequality remains unchanged: $\partial \theta^{*} / \partial a>0$. The income effect becomes more important relative to the discrimination effect. Consequently, a higher share of the population decides to vaccinate. To summarize, vaccination discrimination is more likely to occur in societies that are poor or face substantial income inequality.

\section{Perfect price discrimination}

In this section we consider the case where the monopolist can observe individual income. Without externality, this induces efficiency and enables him to obtain the entire rent. Although this represents a benchmark case, it nevertheless deserves particular attention because multi-tier pricing is pervasive in vaccine markets (Russell (2002)). This observation holds for national markets but even more so at the international level, where developing countries receive vaccines at significantly lower prices than developed countries. Of course, the mechanisms of our model are also valid in such an international context, if an international link exists between the infection probabilities. ${ }^{10}$

Again, there is a two stage game. Analyzing the impact of expectations on demand is little more involved with perfect price discrimination because demand has to be determined for every possible price schedule that may be offered. The following lemma demonstrates that there is a unique expectation for every relevant price schedule.

\footnotetext{
${ }^{10}$ The recent outbreak of SARS in China and its spread to Europe and, in particular, North America dramatically demonstrates the correlation between infection risks.
} 
Lemma 3 The monopolist offers a price schedule of the following type:

$$
p_{m}(\theta ; \bar{\theta})=\left\{\begin{array}{cc}
z_{\theta}(1-\bar{\theta})+z_{a}\left(a_{H}-\theta \Delta\right) & \text { for } \theta \leq \bar{\theta} \\
\infty & \text { for } \theta>\bar{\theta}
\end{array}\right.
$$

Given this schedule, individuals rationally expect $\bar{\theta}$ to be the immunization rate.

Proof. Before addressing expectations we have to show that it is sufficient to analyze price schedules like those mentioned above. First, note that the schedule will have a cut-off value of income $\bar{a} \in\left[a_{L}, a_{H}\right]$ such that all individuals with incomes higher than $\bar{a}$ will demand vaccination and those with lower incomes will not. If this were not the case, the monopolist would benefit from reallocating vaccinations. At $\bar{a}$ the monopolist will demand the entire willingness to pay $p\left(\theta^{e}, \bar{a}\right)$. For incomes exceeding $\bar{a}$ he simply adds the income effect $z_{a}(a-\bar{a})$ and again obtains the entire rent. Individuals whose incomes fall short of $\bar{a}$ receive no offer. Using the relationship $a=a_{H}-\theta \Delta$, the relevant price schedules may be written as in equation (8).

Given this schedule, the (symmetric) expectation $\theta^{e}$ can never exceed $\bar{\theta}$ but may be lower. So, consider that $\theta^{e}<\bar{\theta}$. Then the willingness to pay of type $\theta$ is $p\left(\theta^{e}, \theta\right)=$ $z_{\theta}\left(1-\theta^{e}\right)+z_{a}\left(a_{H}-\theta \Delta\right)>z_{\theta}(1-\bar{\theta})+z_{a}\left(a_{H}-\theta \Delta\right)=p_{m}(\theta ; \bar{\theta})$. Since this holds for all $\theta \leq \bar{\theta}$, all individuals with income higher than $a_{H}-\bar{\theta} \Delta$ will vaccinate contradicting $\theta^{e}<\bar{\theta}$. Thus, $\theta^{e}=\bar{\theta}$ results.

By offering a price schedule as shown in equation (8), the monopolist sets not only prices but also the quantity offered in the market. As $\bar{\theta}$ is unique, optimization over $\bar{\theta}$ completes the analysis. The objective function is given by

$$
\Pi(\bar{\theta})=z_{\theta}(1-\bar{\theta}) \bar{\theta}+z_{a} \int_{0}^{\bar{\theta}}\left(a_{H}-\theta \Delta\right) d \theta
$$

Optimization with respect to $\bar{\theta}$ yields

$$
\theta^{p p d}=\frac{z_{\theta}+z_{a} a_{H}}{2 z_{\theta}+z_{a} \Delta}
$$

Qualitatively, the comparative static properties of $\theta^{p p d}$ compare with those of $\theta^{*}$. Comparing equations (6) and (10) unambiguously reveals $\theta^{p p d}>\theta^{*}$. The monopolist's ability to demand prices that are conditional on the willingness to pay reduces the prevalence of 
the disease. This is well in line with standard monopoly theory. However, the following proposition contrasts with it, highlighting the peculiarity of the vaccine market, namely, the external effect.

Proposition 1 For a sufficiently strong external effect, $z_{\theta}>z_{a} a_{L}$, a perfect price discriminating monopolist is socially inefficient, i.e. $\theta^{\text {ppd }}<1$.

As the proof is straightforward, we only provide the intuition and a graphical illustration: with negative network effects increasing demand not only reduces the price for the marginal consumer, it also reduces the willingness to pay of all other consumers. Consider figure 1. Instead of serving $\theta^{p p d}$ suppose that the monopolist covers the entire market. The additional rent he gains is given by area A. But, as the higher share of vaccinated individuals reduces the willingness to pay, all individual prices are reduced. He loses rent that amounts to area B. With full immunization the monopolist is clearly worse off.

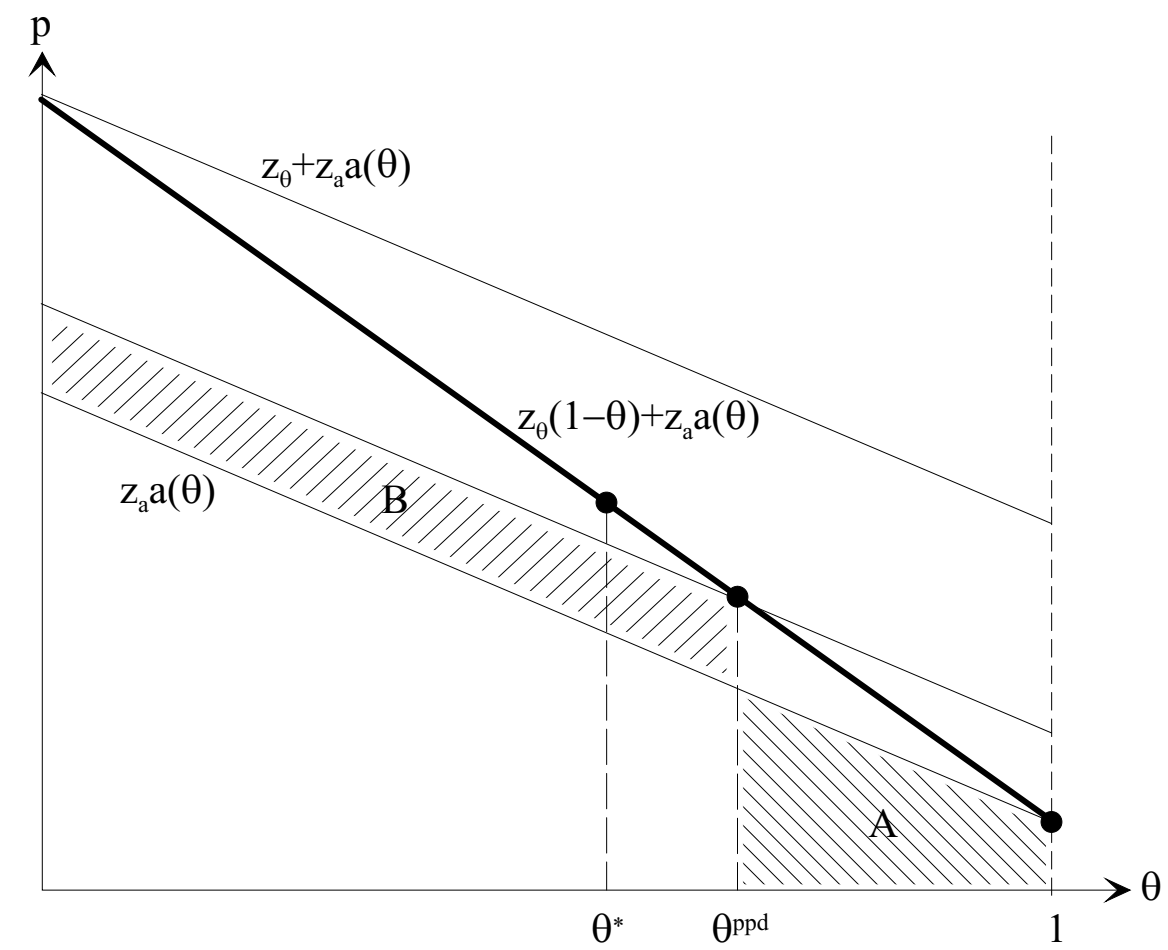

Figure 1: The case of perfect price discrimination with vaccination externality. 
The results of this section may simply be summarized by $\theta^{*}<\theta^{p p d} \leq 1$. Both inequalities require some further discussion. First, allowing the monopolist to perfectly price discriminate improves access to vaccines and is thus socially desirable. In an international context price discrimination is the rule rather than the exception. However, when providing vaccines to developing countries at lower rates than to developed countries the monopolist risks undermining prices in developed countries, e.g. by re-imports. This may force the monopolist back to the uniform monopoly price. But developed countries have an incentive to prohibit re-imports since higher monopoly profits in the case of perfect price discrimination facilitate stronger R\&D incentives in a dynamic framework (see Kremer (2002, pp. 76-77)). Of course, the same argument holds for arbitrage prevention if price discrimination is employed at the national level. Second, although perfect price discrimination yields higher welfare than standard monopoly, public health intervention may still be necessary to correct for the externality.

\section{Public policy}

Obviously, within our setting of zero marginal cost, the socially optimal policy would be to have the monopolist cover the whole market. We now discuss the consequences of two standard public health interventions, namely price subsidies and mandatory vaccination programs. To evaluate their benefits, we analyze their potential to increase the degree of immunization in society.

\subsection{Price subsidies}

Consider a policy of paying the monopolist a per unit subsidy of size $s>0$. This is usually a standard tool for alleviating the inefficiency caused by monopoly and a Pigouvian cure for the vaccination externality. Unfortunately subsidies do not work very well in the market for vaccines since the positive effect of the subsidy is opposed by the prevalence effect: the increased demand due to the subsidy reduces the prevalence of the disease and thereby the willingness to pay for vaccination. Things get worse when the subsidy is to be financed by taxation. Consider, for example, a head tax of size $T$. The income 
distribution in this case shifts to $\left[a_{L}-T, a_{H}-T\right]$ creating a negative income effect. The government budget constraint is given by $T=\theta s$. Thus the monopolist now faces a willingness to pay of

$$
p(\theta ; s)=z_{\theta}(1-\theta)+z_{a}\left(a_{H}-\theta s-\theta \Delta\right) .
$$

He actually receives $p(\theta ; s)+s$. If there is a positive subsidy, the monopolist chooses the price such that

$$
\theta^{s}=\frac{z_{\theta}+z_{a} a_{H}+s}{2\left(z_{\theta}+z_{a} s+z_{a} \Delta\right)}
$$

Proposition 2 There exists a critical income effect $z_{a}^{\text {crit }} \in(0,1)$ such that $\theta^{s}<(=,>)$ $\theta^{*}$ if $z_{a}>(=,<) z_{a}^{\text {crit }}$.

Proof. In principle $\theta^{s}=\theta^{*}$ could be solved for $z_{a}$. Since the actual size of $z_{a}^{\text {crit }}$ is of minor interest, we study two benchmark cases and apply a continuity argument. ${ }^{11}$ To decide on the effectiveness of the subsidy we have to compare $\theta^{s}$ with the laissez-faire share $\theta^{*}$ of equation (6):

$$
\theta^{s}-\theta^{*}=\frac{s}{2} \frac{z_{\theta}\left(1-z_{a}\right)+z_{a} \Delta-z_{a}^{2} a_{H}}{\left(z_{\theta}+z_{a} s+z_{a} \Delta\right)\left(z_{\theta}+z_{a} \Delta\right)}
$$

Since the denominator of the right hand side of equation (13) is always positive, the sign of $\theta^{s}-\theta^{*}$ is determined by the numerator: if $z_{a}=0$ the numerator turns out to be $z_{\theta}>0$. The problem of discrimination is reduced by Pigouvian subsidies, since there is no income effect to offset the positive effect of the subsidy. This coincides with the result when a public budget constraint is not considered. More interesting, if $z_{a}=1$, then $\theta^{s}<\theta^{*}$. Discrimination is further increased by subsidizing vaccines. This is due to the income effect caused by financing the subsidy. By continuity, there exists some value $z_{a}^{\text {crit }} \in(0,1)$ such that the subsidies have no effect. In this case, the positive price effect of the subsidy on demand is exactly offset by the two negative effects, the prevalence effect and the financing effect. If the income effect is sufficiently large, i.e. $z_{a}>z_{a}^{c r i t}$, a subsidy makes things even worse.

$$
{ }^{11} z_{a}^{c r i t}=\frac{1}{2 a_{H}}\left(\Delta-z_{\theta}+\sqrt{z_{\theta}^{2}+2 z_{\theta}\left(a_{H}+a_{L}\right)+\Delta^{2}}\right) .
$$


This is in contrast with the classical regulatory arguments, where Pigouvian subsidies are applied to correct for the inefficiencies due to the externality. This extreme effect was not previously known in the theory of vaccinations. Philipson (2000, p. 1777), for example, states that subsidies are limited in their impact in dynamic settings, but that they may have an effect in the short-run or out of steady state. In our static setting, we have shown - strengthening this result - that subsidies may have no effect or may even have a negative effect. In a related paper, Philipson and Mechoulan (2003) point to another pitfall of Pigouvian subsidies, namely, the distortion of R\&D incentives.

\subsection{Mandatory vaccination}

Another public policy usually suggested is mandatory vaccination. If mandatory vaccination programs do not cover the whole population, the individuals vaccinated reduce the infection probability of the susceptible. The willingness to pay is reduced, i.e. mandatory demand crowds out voluntary demand. This is a standard argument for why it is difficult to eradicate a disease by mandatory vaccination if not the entire population is included in the program (see e.g. Philipson (2000, p. 1781)). This argument also applies to the model presented here if the social planner has no information about individual income levels. But consider that income is observable, then a program is much more effective than usual. Since the individuals differ in income the public program may only cover the poor and the monopolist the rich. ${ }^{12}$

Let $m \in[0,1]$ be the share of mandatory vaccinated individuals. Consider that these are the 100 times $m$ percent poorest in the society. The willingness to pay (of the rich) is now given by

$$
p(\theta ; m)=z_{\theta}(1-\theta-m)+z_{a}\left(a_{H}-\theta \Delta\right) .
$$

\footnotetext{
${ }^{12}$ We assume that the social planner can observe income, while the monopolist cannot, or does not, use this information. As mentioned above, perfect price discrimination yields the same results qualitatively. Since vaccination discrimination is lower, the optimal program with perfect price discrimination will be smaller in size, but may still be necessary.
} 
The optimum is obtained by differentiation with respect to $\theta$ and is attained if

$$
\theta^{m}=\frac{(1-m) z_{\theta}+z_{a} a_{H}}{2\left(z_{\theta}+z_{a} \Delta\right)}
$$

The overall share of vaccinated individuals is given by $\min \left\{1, m+\theta^{m}\right\}$. If $m+\theta^{m}<1$, then the effect of extending the mandatory vaccination program on the share of vaccinated individuals is clearly positive: $d\left(m+\theta^{m}\right) / d m>0$.

Proposition 3 With mandatory vaccination programs full immunization is achieved at participation rates strictly smaller than 1.

Proof. Solving $m+\theta^{m}=1$ for $m$ yields

$$
\bar{m}=\frac{z_{\theta}+z_{a} \Delta-z_{a} a_{L}}{z_{\theta}+2 z_{a} \Delta}
$$

The equivalence $\bar{m}<1 \Leftrightarrow z_{a} a_{H}>0$ proves the assertion.

Mandatory vaccination is more effective than in other models, e.g. Geoffard and Philipson (1997), since the negative effect of the externality is reduced by the still high income effect. As long as the income effect is positive, a residual demand $\theta^{m}>0$ served by the monopolist remains. Note that the government's information about individual income heterogeneity enables it to counter the strategic pricing behavior of the monopolist originating precisely from such differences among individuals. The proposition provides an efficiency based argument for distribution-oriented public health vaccination programs like those typically supported by the WHO or the Worldbank.

In line with our comparative static results on income inequality, the share of the population to be included in the program is higher, the higher income inequality. If a society has a high amount of inequality, it is accompanied by a serious amount of vaccination discrimination. Thus, the mandatory vaccination program must be relatively large for full immunization. Of course, if income inequality is relatively low, there is no need for a public vaccination program, since the monopolist already serves the entire market. 


\section{Conclusion}

We presented a simple static model to study the effects of monopoly power on the supply side in the market for vaccines. We highlighted the importance of income inequality when analyzing the monopolist's incentive to exploit the external effect of vaccinations to maximize profits.

In the monopoly solution the poor are discriminated against, i.e., remain susceptible, in order to increase the willingness to pay of the rich. Interpreting individuals as countries, the developing countries are strategically left without immunization. Discrimination was found to be more severe if the prevalence elasticity of demand is high, i.e., when the income effect is low or the impact of the external effect is high. Societies with low average wealth or high income inequality are left with a high share of susceptible individuals. With perfect price discrimination the prevalence of the disease will be lower. But, in contrast to the standard monopoly model without external effects, the outcome may still be inefficient.

If the social planner is not informed about the individual income levels, he is left with two policy alternatives - Pigouvian subsidies and mandatory vaccination. Unfortunately, subsidies are of limited use since the positive price effect is opposed by two negative effects, the prevalence effect and the income effect. In some cases subsidies make things even worse, raising doubts about whether Pigouvian subsidies are appropriate at all. As usual, mandatory vaccination programs fail to eradicate the disease if not the entire population is included in the program. Things change dramatically when the social planner is informed about individual income. The public health interventions may then be conditional on income. A mandatory program covering the poor only yields full vaccination at participation rates that are strictly smaller than one. Thus, when income is observable, mandatory vaccination programs strictly dominate Pigouvian subsidies. This provides an efficiency-based argument for public health vaccination programs directed towards the poor or, within an international context, towards poor countries, like the ones advocated and carried out by the Worldbank or the WHO. 


\section{References}

[1] Bensaid, Bernard and Jean-Philippe Lesne, 1996, Dynamic Monopoly Pricing with Network Externatilies, International Journal of Industrial Organization 14(6), 837855.

[2] Brito, Dagobert L.; Sheshinski, Eytan and Michael D. Intriligator, 1991, Externalities and Compulsory Vaccinations, Journal of Public Economics 45(1), 69-90.

[3] BusinessWeek Online, 2002, December 9, Vaccines are Getting a Booster Shot (http://www.businessweek.com/magazine/content/02_49/b3811060.htm)

[4] Cabral, Luis M. B.; Salant, David J. and Glenn A. Woroch, 1999, Monopoly Pricing with Network Externalities, International Journal of Industrial Organization 17(2), 199-214.

[5] England, Sarah; Kaddar, Miloud; Nigam, Ashok and Matilde Pinto, 2001, Practice and Policies on User Fees for Immunization in Developing Countries, World Health Organization, Geneva.

[6] Francis, Peter J., 1997, Dynamic Epidemiology and the Market for Vaccinations, Journal of Public Economics 63(3), 383-406.

[7] Geoffard, Pierre-Yves and Tomas Philipson, 1997, Disease Eradication: Private versus Public Vaccination, American Economic Review 87(1), 222-230.

[8] Kauf, Teresa L., 1999, Price Discrimination and Bargaining Power in the U.S. Vaccine Market, Implications for Childhood Immunization Policy, The Quarterly Review of Economics and Finance 39(2), 249-265.

[9] Kremer, Michael, 2002, Pharmaceuticals and the Developing World, Journal of Economic Perspectives 16(4), 67-90.

[10] Mason, Robin, 2000, Network Externalities and the Coase Conjecture, European Economic Review 44(10), 1981-1992. 
[11] Médecins Sans Frontières, 2003, Press Release Feb 13, 2003.

(http://www.msf.org/content/page.cfm?articleid=FE4CC291-AEC3-4E78A15E41777D91BFDA)

[12] Philipson, Tomas, 1996, Private Vaccination and Public Health: An Emprirical Examination for U.S. Measles, Journal of Human Resources 31(3), 611-630.

[13] —, 2000, Economic Epidemiology and Infectious Diseases, in: A. J. Culyer and J. P. Newhouse, eds., Handbook of Health Economics, Vol. 1(B), Elsevier Science, Amsterdam.

[14] Philipson, Tomas and Stéphane Mechoulan, 2003, Intellectual Property \& External Consumption Effects: Generalizations from Pharmaceutical Markets, NBER Working Paper No. 9598, Cambridge, Massachusetts.

[15] Pratt, John W., 1964, Risk Aversion in the Small and in the Large, Econometrica $32(1-2), 122-136$.

[16] Reiss T. and E. Strauss, 1998, Vaccines - Patenting Dynamics of a Powerful Healthcare Tool, Expert Opinion on Therapeutic Patents 8(8), 951-958.

[17] Russel, Phillip K., 2002, Developement of Vaccines to Meet Public Health Needs: Incentives and Obstacles, Risk 7(summer). (http://www.piercelaw.edu/risk/vol7/summer/russell.htm)

\section{Appendix}

Here we provide a micro foundation for our reduced form approach. We argue that a vaccination can be seen as an insurance against the disease. Using this, we will derive a sufficient condition for the willingness to pay being increasing in income. Furthermore we show that under this condition a unique equilibrium always exists.

\section{Vaccination as insurance}

Consider an individual with an original income of $a>0$, which reflects individual produc- 
tivity or wage-earning abilities, and preferences which obey the von Neumann-Morgenstern axioms. The individual is exposed to the threat of becoming infected with a transmittable disease. The probability of infection is given by $\pi \in(0,1]$, which is taken to be exogenous to the individual. ${ }^{13}$ The monetary loss from infection depends on income, $\beta=\beta(a)$. It is sensible to assume that $\beta>0$ and $\beta^{\prime} \in[0,1]$, since illness will lead to absence from work for a certain time. Hence, a high income individual will lose (weakly) more than a low income individual. A vaccine is available that yields perfect protection against the disease and has no side effects. The price for being vaccinated is denoted $p$. Then, the utility for a vaccinated individual with income $a$ is given by

$$
u=u(a-p)
$$

The individual decides to vaccinate, if, and only if, the utility $u$ exceeds the expected utility $E u$ of remaining without protection, where

$$
E u=\pi u(a-\beta(a))+(1-\pi) u(a)
$$

The decision to vaccinate amounts to the choice between the certain outcome and the original risky outcome. Thus, the willingness to pay for vaccinations $p(\pi, a)$ equals the sum of two components, the increase in expected income, $\pi \beta$, and the risk premium. Applying the approximation formula for the risk premium derived by Arrow and Pratt (see Pratt (1964)), we have $p(\pi, a) \approx \pi \beta-\frac{u^{\prime \prime}(E X)}{u^{\prime}(E X)} \frac{\operatorname{Var}(X)}{2}$, where $E X=a-\pi \beta$ and $\operatorname{Var}(X)=\pi(1-\pi) \beta^{2}$. Then, for a given infection probability, the willingness to pay globally increases in income if for all $a>0$ the following condition holds:

$$
\frac{u^{\prime \prime \prime}}{u^{\prime \prime}}-\frac{u^{\prime \prime}}{u^{\prime}}>2 \beta^{\prime} \frac{u^{\prime} /\left(u^{\prime \prime}(1-\pi)\right)-\beta}{\left(1-\pi \beta^{\prime}\right) \beta^{2}}
$$

The numerator of the right hand side is always negative while the denominator is positive. In the case of constant absolute risk aversion, the left hand side is zero, implying a strictly increasing willingness to pay for vaccinations if $\beta^{\prime}>0$. If the utility function

\footnotetext{
${ }^{13} \mathrm{Of}$ course, in equilibrium, this probability will depend on the number of susceptible individuals. This issue is addressed below. Like above, $\pi$ can be interpreted as the (symmetric) expectation about the infection risk.
} 
exhibits constant relative risk aversion, $\beta^{\prime}$ must be sufficiently large for the willingness to pay to be non-decreasing in income.

In the following we will assume that condition (19) holds. Furthermore we assume sorting of individuals, $\partial \theta / \partial a<0$, and, reflecting the vaccination externality, $\partial \pi / \partial \theta<0$. The following two paragraphs compare to the treatment in section 3 (see e.g. lemma 1).

\section{Expectations}

Consider that the price $p$ is exogenous. Moreover assume that $(\bar{\pi}, \bar{a})$ solves $u(\bar{a}-p)-$ $E u(\bar{\pi}, \bar{a})=0$, where $\bar{\pi}=\pi(\theta(\bar{a}))$. Then expectations will be such that $\pi^{e}=\bar{\pi}$, i.e. $(\bar{\pi}, \bar{a})$ is an equilibrium of the second stage game.

Proof: We have $u(\bar{a}-p)-E u(\bar{\pi}, \bar{a})=0$, where $\bar{\pi}=\pi(\theta(\bar{a}))$. Suppose that $\pi^{e}>\bar{\pi}$. Then $u(\bar{a}-p)-E u\left(\pi^{e}, \bar{a}\right)>0$. Given the price $p$, the former indifferent individual with income $\bar{a}$ now obtains a positive rent. Since the willingness to pay is increasing in income there exists an income level $\widehat{a}<\bar{a}$ with $u(\widehat{a}-p)-E u\left(\pi^{e}, \widehat{a}\right)=0$. It follows that $\widehat{\theta}>\bar{\theta}$ and with it $\widehat{\pi}<\bar{\pi}$. Thus expectations with $\pi^{e}>\bar{\pi}$ can never be confirmed. A similar argument applies when $\pi^{e}<\bar{\pi}$ proving $\pi^{e}=\bar{\pi}$.

\section{Uniqueness}

Consider that the price $p$ is exogenous. Assume that $u(\bar{a}-p)=E u(\bar{a}, \pi(\theta(\bar{a})))$. Then $\bar{a}$ is unique.

Proof: Consider an income $\widehat{a}>\bar{a}$. We know from above that $u(\widehat{a}-p)-E u(\widehat{a}, \pi(\theta(\bar{a})))>$ 0 . Since $\widehat{a}>\bar{a} \Leftrightarrow \widehat{\theta}<\bar{\theta} \Leftrightarrow \widehat{\pi}>\bar{\pi} \Leftrightarrow \operatorname{Eu}(\widehat{a}, \pi(\theta(\widehat{a})))<E u(\widehat{a}, \pi(\theta(\bar{a})))$ we have $u(\widehat{a}-p)-E u(\widehat{a}, \pi(\theta(\widehat{a})))>u(\widehat{a}-p)-E u(\widehat{a}, \pi(\theta(\bar{a})))>0$. Thus no income $\widehat{a}>\bar{a}$ can be a solution of our problem. As the same applies to every $\widehat{a}<\bar{a}, \bar{a}$ is unique.

\section{Consequences}

From our analysis above we know that those who demand vaccination are, as long as condition (19) holds, the rich. Of course, it is also possible to construct the theoretical case where the willingness to pay decreases with income, e.g. if $\beta^{\prime}=0$ and constant relative risk aversion is assumed. However, this is contradicted by empirical evidence. A direct implication of the increasing willingness to pay is uniqueness. This is different 
from models with positive externalities where multiple equilibria may occur. Having these results it is straightforward to generalize our reduced form to some function $p(\theta, a)$ with $\partial p / \partial \theta<0$ and $\partial p / \partial a>0$ implying a downward sloping aggregate demand schedule. 